\title{
Independent activation of MAP kinase and MPF during the initiation of meiotic maturation in pig oocytes
}

\author{
J. Ye, A. P. F. Flint, M. R. Luck* and K. H. S. Campbell \\ Division of Animal Physiology, School of Biosciences, University of Nottingham, Sutton Bonington \\ Campus, Loughborough LE12 5RD, UK
}

\begin{abstract}
Mitogen-activated protein (MAP) kinase is universally activated during oocyte maturation in all vertebrates studied to date. Its role in the resumption of meiosis and in the activation of maturation-promoting factor (MPF) remains unclear, especially in domestic species such as the pig. This study aimed to clarify the temporal and causal relationships between MAP kinase and MPF during meiotic maturation, particularly during the resumption of meiosis. Pig oocytes were matured synchronously in culture by treatment with cycloheximide. Kinase activities were analysed using a sensitive in vitro double-kinase assay and the specific MAP kinase pathway inhibitor U0126. MAP kinase and MPF were activated simultaneously at the time of germinal vesicle breakdown (GVBD; $6 \mathrm{~h}$ after removal of cycloheximide); they reached significant activity at $7 \mathrm{~h}$ $(P<0.05)$. The activities increased in parallel during
\end{abstract}

GVBD (6-10 h) and peaked when the oocytes entered metaphase I (MI; $10 \mathrm{~h})$. Whereas MAP kinase remained stable at peak activity thereafter, MPF activity significantly declined during the MI-MII transition (16-20 h) but increased to a second peak at MII (22 h). MAP kinase activity in denuded and cumulus-cell enclosed oocytes was completely inhibited by 20 and $80 \mu \mathrm{mol} U 0126 \mathrm{I}^{-1}$, respectively. Oocytes without detectable MAP kinase activity underwent normal GVBD in terms of nuclear morphology and timing, although later meiotic stages were abnormal. The kinetics of MPF activity during GVBD were unaffected by U0126. This study has demonstrated that MAP kinase is activated simultaneously with MPF at GVBD, but that its activation is not essential for the activation of MPF nor for the resumption of the first meiosis in pig oocytes.

\section{Introduction}

In mammals, fully grown oocytes are arrested at the first meiotic prophase, the so-called germinal vesicle (GV) stage of development, which is usually assumed to be equivalent to the G2-M transition in mitosis (Moor et al., 1990). Oocytes at this stage are immature and cannot be fertilized normally. They have to develop further from the first meiotic prophase to the second meiotic metaphase (MII), at which time they are arrested again and become capable of responding normally to spermatozoa. The period of development between these two meiotic blocks is usually described as the period of meiotic maturation. During the course of maturation, oocytes undergo marked morphological changes associated with the meiotic cell cycle, among which germinal vesicle breakdown (GVBD) is usually regarded as the first indicator of progression.

The inter- and intra-cellular processes underlying oocyte maturation have not been elucidated. An advance towards understanding the molecular basis of oocyte

*Correspondence

Email: Martin.Luck@nottingham.ac.uk meiotic maturation is the purification and identification of maturation-promoting factor (MPF; Masui and Markert, 1971) as a serine-threonine protein kinase comprising Cdc2 (the catalytic subunit) and cyclin B (the regulatory subunit; Gautier et al., 1988; Lohka et al., 1988). This is thought to be a universal G2$\mathrm{M}$-phase regulator for both meiosis and mitosis in all eukaryotic cells (Nurse, 1990). The Cdc2 kinase activity is directed against serine and threonine residues in the motif S-TP flanked by basic residues (Langan et al., 1989). The motif is well represented in histone $\mathrm{H} 1$ which acts as an excellent in vitro substrate for the MPF Cdc2 kinase (Nurse, 1990), and is commonly used to assess the activity of MPF (Naito and Toyoda, 1991). MPF activity changes with the phosphorylation status of Cdc2 at threonine 14-tyrosine 15 (inhibitory phosphorylation by Wee1 or Wee1-like kinase or Myt1; activating dephosphorylation by Cdc25), and threonine 161 (activating phosphorylation by cyclin-dependent kinase activity), after formation of the Cdc2-cyclin B complex (for reviews, see Puri et al., 1999; Nebreda and Ferby, 2000; Yamashita et al., 2000). Irrespective of the generality of the molecular structure of MPF, its formation and activation during oocyte maturation vary 
from species to species (Yamashita et al., 2000). The signal transduction pathways linked to MPF are poorly understood, especially in domestic species.

In addition to MPF, other kinases may be involved in oocyte maturation, notably mitogen-activated protein (MAP) kinase. MAP kinase is a family of serine-threonine protein kinases, which directly integrates extracellular signals with the cell-cycle control system (for reviews, see Ferrell, 1996; Denhardt, 1999). The best-characterized forms of MAP kinase are p44 extracellular signal regulated kinase 1 (p44 Erk1) and p42 Erk2, which play a central role in signalling cell proliferation induced by growth factors. For simplicity, the generic term MAP kinase (MAPK) is used in this study for Erk1 and Erk2. The activation of MAP kinase results from its phosphorylation at threonine and tyrosine residues by a dual specificity kinase called MAP kinase-Erk kinase (MEK), which is in turn activated by Raf or Mos in oocytes (Barrett et al., 1990; Neberda and Hunt, 1993; Posada et al., 1993; Ferrell, 1996). MAP kinase activity is usually measured by in vitro assay using bovine myelin basic protein (MBP) as the substrate (Fissore et al., 1996), or by western blot analysis with antisera detecting the phosphorylated forms. Activation of MAP kinase has been a universally observed phenomenon during meiotic maturation in vertebrate oocytes (Masui, 2000; Nebreda and Ferby, 2000; Yamashita et al., 2000). The Mos-MAP kinase pathway is believed to comprise elements of the putative cytostatic factor (Masui and Markert, 1971), which maintains MPF activity and arrests oocytes at MII in vertebrates (Sagata et al., 1989; Masui, 2000). However, it is still not clear whether MAP kinase is involved in the initiation of meiotic maturation (GVBD).

In Xenopus oocytes, Mos-MAP kinase normally participates in MPF activation by initiating the activation of pre-MPF (the inactive form of $\mathrm{Cdc} 2-$ cyclin B complex) and GVBD (Palmer et al., 1998; Nebreda and Ferby, 2000), but it may also be disassociated from MPF activation and GVBD (Fisher et al., 1999; Gross et al., 2000). The relationships between MAP kinase and MPF are more elusive in mammalian oocytes. Although it is generally accepted that MAP kinase activity is not essential for the initiation of meiotic maturation in mouse oocytes (for reviews, see Sun et al., 1999; Yamashita et al., 2000), there is no agreement on the role of MAP kinase in relation to MPF in the early events of meiotic maturation in domestic species. For example, MAP kinase may be activated at the same time as MPF at GVBD in bovine oocytes (Fissore et al., 1996; Motlik et al., 1998; Meinecke et al., 2001; Wehrend and Meinecke, 2001), but MAP kinase is activated after MPF activation and GVBD in goat oocytes (Dedieu et al., 1996).

Pigs are polyovular and have a lengthy oocyte maturation period; therefore they are a suitable domestic model for biochemical studies of oocyte meiotic maturation. MAP kinase is reportedly activated after (Inoue et al.,
1995), during (Motlik et al., 1998; Lee et al., 2000), or before (Inoue et al., 1998; Wehrend and Meinecke, 2001; Sugiura et al., 2002) GVBD or MPF activation in pig oocytes. Furthermore, the activity of MAP kinase may increase (Wehrend and Meinecke, 2001) or decrease (Inoue et al., 1995; Li et al., 2002) during the MlMII transition. Studies with specific inhibitors of $\mathrm{Cdc} 2$ kinase, such as roscovitine and butyrolactone, have indicated that MPF might induce the activation of MAP kinase (Krischek and Meinecke, 2001; Kubelka et al., 2002). However, with specific inhibitors of MEK-MAP kinase such as PD 098059 and U0126, a reversal of the activation sequence between MPF and MAP kinase has been obtained (Shimada et al., 2001; Tomek et al., 2002). Conversely, some studies indicate that artificial activation of MAP kinase is sufficient for GVBD (Inoue et al., 1998), even when the activation of MPF is inhibited (Kubelka et al., 1996; Motlik et al., 1998; Sun et al., 2002), whereas others imply that MAP kinase might not be necessary for such an event (Shimada et al., 2001).

Separate assessments of MAP kinase and MPF activity during oocyte maturation may not reveal the temporal relationship between them. Ideal oocyte samples are those with clearly defined meiotic stages. However, pig oocytes are meiotically heterogeneous in vivo before selection for ovulation (Guthrie and Garrett, 2000) and are asynchronous in vitro in conventional maturation culture systems (Grupen et al., 1997; Ye et al., 2002). An in vitro culture system has been developed which synchronizes meiotic progression and is particularly suitable for analysing meiotic signalling pathways in pig oocytes (Ye et al., 2002). On the basis of this synchronization culture system and using a reliable and sensitive doublekinase assay and the specific MEK-MAP kinase inhibitor U0126, the present study has investigated the temporal and causal relationships between MPF and MAP kinases during meiotic maturation, particularly the resumption of meiosis, in pig oocytes.

\section{Materials and Methods}

All chemicals and reagents were purchased from SigmaAldrich (Poole) unless otherwise stated.

\section{In vitro maturation and synchronization of pig oocytes}

Tissue handling, oocyte collection, removal of cumulus cells, and the conventional and synchronized culture conditions were as described by Ye et al. (2002). Briefly, pig ovaries were collected from a local commercial abattoir. Follicles of 3-5 mm in diameter with a translucent appearance and extensive vascularization were aspirated using a 21-gauge needle attached to a $5 \mathrm{ml}$ syringe primed with $0.5 \mathrm{ml}$ Dulbecco's phosphate buffered saline (DPBS, $\mathrm{Ca}^{2+}$-free; supplemented with $10 \mu \mathrm{g}$ cycloheximide $\mathrm{ml}^{-1}$ for the synchronization system). 
Cumulus-oocyte complexes (COCs, with more than three intact and compact cumulus layers) or denuded oocytes (DOs, oocytes from COCs upon removal of cumulus cells) were cultured in a defined maturation medium (DM; M199 containing Earle's salts, 25 mmol Hepes $\mathrm{I}^{-1}$ and sodium bicarbonate, $3 \mathrm{mmol}$ L-glutamine $\mathrm{I}^{-1}$, $0.1 \%(\mathrm{w} / \mathrm{v}) \mathrm{BSA}, 100$ iu penicillin $\mathrm{ml}^{-1}, 0.1 \mathrm{mg}$ streptomycin $\mathrm{ml}^{-1}$ and $0.1 \mathrm{ng}$ pig $\mathrm{LH} \mathrm{ml} \mathrm{m}^{-1}(\mathrm{pLH}$; USDA, Beltsville, MD)) at a ratio of one oocyte per $10 \mu \mathrm{l}$ DM. COCs were first preincubated in DM containing $5 \mu \mathrm{g}$ cycloheximide $\mathrm{ml}^{-1}$ for $12 \mathrm{~h}$ to synchronize maturation. Oocytes (COCs or DOs) were then further cultured without cycloheximide for various periods up to $36 \mathrm{~h}$. All culture drops containing oocytes were covered with a thin layer of mineral oil pre-equilibrated with DM and incubated in $5 \% \mathrm{CO}_{2}$ in humidified air at $39^{\circ} \mathrm{C}$.

\section{Oocyte staining and assessment of meiotic maturation}

One dish of cultured oocytes (20-25) was withdrawn from the incubator at each time point. Half of the oocytes (ten) were sampled for kinase assays (see below) and the remaining oocytes were collected for morphological examination. Meiotic maturation was evaluated as described previously after fixing and staining with lacmoid under a phase-contrast microscope at $\times 400$ 1000 magnification (Ye et al., 2002). Meiotic stages were classified as GV (GVI-GVIV), GVBD (diakinesis and prometaphase I), MI, anaphase I-telophase I (AI-TI), and MII. Trypan blue staining was used to evaluate oocyte viability by uptake or exclusion of the stain (Ye et al., 2002).

\section{Preparation of oocyte lysate for kinase assay}

Oocytes (COCs) were denuded of cumulus cells by briefly vortexing in a warm buffer containing $0.1 \%$ hyaluronidase (type IV), $2 \mathrm{mmol}^{\mathrm{EDTA} \mathrm{I}} \mathrm{I}^{-1}(\mathrm{pH} 7.3), 3 \mathrm{mmol}$ sodium citrate $\mathrm{I}^{-1}, 125 \mathrm{mmol} \mathrm{NaCl} \mathrm{I}{ }^{-1}$ and $10 \mathrm{mmol}$ $\mathrm{Na}_{2} \mathrm{HPO}_{4} \mathrm{I}^{-1}$. After washing twice in $\mathrm{Ca}^{2+}$-free DPBS containing $0.1 \%$ polyvinyl alcohol, ten oocytes were collected with minimal washing medium $(<1 \mu \mathrm{l})$ using a fine pipette into $5 \mu \mathrm{l}$ ice-cold lysis buffer containing 45 mmol $\beta$-glycerophosphate $\mathrm{I}^{-1}(\mathrm{pH} 7.3), 12 \mathrm{mmol} p$ nitrophenylphosphate $\mathrm{I}^{-1}, 20 \mathrm{mmol} 3$-(N-morpholino)propanesulfonic acid (MOPS) $\mathrm{I}^{-1}, 12 \mathrm{mmol} \mathrm{MgCl}_{2} \mathrm{I}^{-1}$, $12 \mathrm{mmol}$ ethyleneglycol bis (2-aminoethyl-ether) tetra acetic acid (EGTA) I-1, $1.4 \mathrm{mmol}$ EDTA I-1, $20 \mathrm{mmol}$ $\mathrm{Na}_{3} \mathrm{VO}_{4} \mathrm{I}^{-1}, 10 \mathrm{mmol} \mathrm{NaF} \mathrm{I}^{-1}, 2 \mathrm{mmol}$ dithiothreitol (DTT) $\mathrm{I}^{-1}, 2 \mathrm{mmol}$ phenylmethylsulphonyl fluoride $\mathrm{I}^{-1}$, $2 \mathrm{mmol}$ benzamidine $\mathrm{I}^{-1}, 20 \mu \mathrm{g}$ leupeptin $\mathrm{ml}^{-1}, 20 \mu \mathrm{g}$ pepstatin $\mathrm{A} \mathrm{ml}^{-1}$ and $20 \mu \mathrm{g}$ aprotinin $\mathrm{ml}^{-1}$. Oocytes were lysed by probe sonication at $5 \mu \mathrm{m}$ for $1.0-1.5 \mathrm{~s}$ and immediately placed on ice. After centrifugation at 13000 r.p.m. $(9000 \mathrm{~g})$ for $5 \mathrm{~s}$, the lysate was stored at $-70^{\circ} \mathrm{C}$.
In vitro MPF and MAP kinase double assay

The activities of MPF and MAP kinase were measured simultaneously using histone $\mathrm{H} 1$ and $\mathrm{MBP}$ as their substrates, respectively. The oocyte lysate was thawed on ice and briefly vortexed when assayed. The kinase reaction was started by adding the oocyte lysate to $5 \mu \mathrm{l}$ kinase assay buffer containing $45 \mathrm{mmol} \beta$ glycerophosphate $\mathrm{I}^{-1}(\mathrm{pH} 7.3), 12 \mathrm{mmol} p$-nitrophenylphosphate $\mathrm{I}^{-1}, 20 \mathrm{mmol}$ MOPS I-1, $12 \mathrm{mmol} \mathrm{MgCl}_{2}$

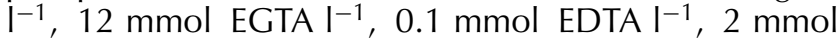
$\mathrm{Na}_{3} \mathrm{VO}_{4} \mathrm{I}^{-1}, 10 \mathrm{mmol} \mathrm{NaF} \mathrm{I}{ }^{-1}, 2 \mathrm{mg}$ histone $\mathrm{H} 1 \mathrm{ml}^{-1}$ $3 \mathrm{mg} \mathrm{MBP} \mathrm{ml}^{-1}, 4 \mu \mathrm{mol}$ protein kinase $\mathrm{A}$ (PKA) $\mathrm{I}^{-1}$ inhibiting peptide (Santa Cruz Biotechnology; Autogen Bioclear, Calne), $4 \mu \mathrm{mol}$ protein kinase $\mathrm{C}$ (PKC) $\mathrm{I}^{-1}$ inhibiting peptide (Promega, Southampton) and $0.5 \mu \mathrm{Ci}$ $\left(34 \mu \mathrm{mol} \mathrm{I}{ }^{-1}\right) \quad\left[\gamma^{-32}\right.$ P]ATP (Amersham Pharmacia Biotech, Amersham). Kinase reaction mixtures were incubated at $37^{\circ} \mathrm{C}$ for $30 \mathrm{~min}$ with gentle shaking. The reaction was stopped by adding $10 \mu \mathrm{l}$ ice-cold $2 \times$ SDS sample buffer $\left(125 \mathrm{mmol}\right.$ Tris $\mathrm{HCl} \mathrm{I}^{-1}(\mathrm{pH}$ $6.8), 200 \mathrm{mmol}$ DTT I-1 $4 \%(\mathrm{w} / \mathrm{v})$ SDS, $0.1 \%(\mathrm{w} / \mathrm{v})$ bromophenol blue and $20 \%$ (w/v) glycerol). After boiling for 4-5 min, the substrates were separated by standard polyacrylamide gel electrophoresis (SDS-PAGE, 15\% gels; Laemmli, 1970) using Mini-Protean II dual slab cell (Bio-Rad, Hercules, CA) under 140 V for 1.5 h. Gels were dried on $3 \mathrm{~mm}$ filters and exposed to phosphor-screens (Kodak; Amersham Pharmacia Biotech). The phosphor images of gels (screens) were captured and the kinase activities were quantified using an FX phosphor image analysis system (Bio-Rad). Freshly isolated GV oocytes or 'hot' (same kinase reaction mixtures with ${ }^{32} \mathrm{P}$ but without oocytes) or 'cold' (same kinase reaction mixtures without ${ }^{32} \mathrm{P}$ and oocytes) blanks were analysed with oocyte samples throughout the assays as kinase negative controls.

\section{Western blotting to detect phospho-MAP kinase (p44Erk1, p42Erk2)}

Oocytes (45 per sample, denuded) were collected into and lysed by briefly vortexing in $20 \mu$ ice-cold $1 \times$ SDS sample buffer containing $1.5 \mathrm{mmol}^{\text {EDTA I-1, }}$ $2 \mathrm{mmol} \mathrm{NaF} \mathrm{I}{ }^{-1}$ and $20 \mathrm{mmol} \mathrm{Na}_{3} \mathrm{VO}_{4} \mathrm{I}^{-1}$ (stored at $-70^{\circ} \mathrm{C}$, if necessary). After boiling for $4-5 \mathrm{~min}$, the lysates were loaded onto $12 \%$ polyacrylamide gels for SDS-PAGE as described above. Proteins were immediately transferred after SDS-PAGE on to nitrocellulose membranes (Schleicher \& Schuell, Keene, NH) using a Mini Trans-Blot electrophoretic transfer cell (BioRad). Membrane blots were blocked in blocking buffer $(5 \%(\mathrm{w} / \mathrm{w})$ non-fat dried milk in Tween Tris-buffered saline (TBST): $0.1 \%(\mathrm{v} / \mathrm{v})$ Tween-20, $20 \mathrm{mmol}$ Tris $\mathrm{HClI}^{-1}$ (pH 7.6) and $137 \mathrm{mmol} \mathrm{NaCl} \mathrm{I}^{-1}$ ) overnight at $4^{\circ} \mathrm{C}$. Active Erk1, 2 MAP kinase was probed by incubating blocked membrane blots with anti-phospho 


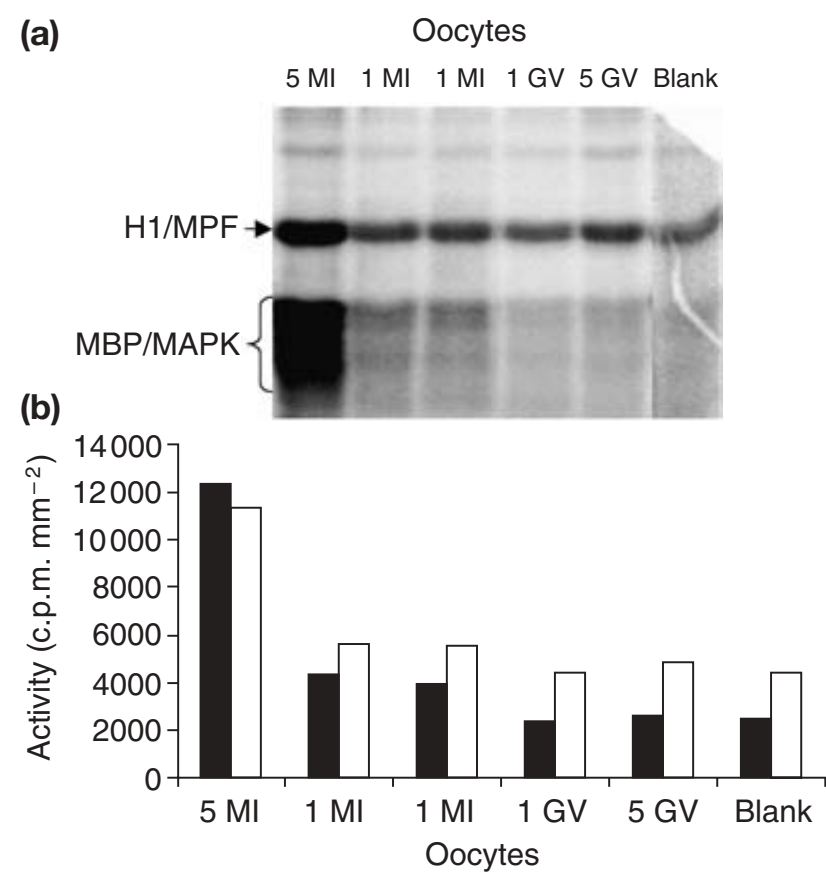

Fig. 1. Sensitivity of in vitro double-kinase assay in pig oocytes. Cumulus-oocyte complexes were first preincubated with cycloheximide for $12 \mathrm{~h}$ (from $0 \mathrm{~h}$, germinal vesicle $(\mathrm{GV})$ ) and then further cultured without cycloheximide for $14 \mathrm{~h}$ (metaphase I (MI)). Oocytes ( 1 or 5 at each stage as indicated) were collected in $5 \mu \mathrm{l}$ ice-cold lysis buffer and sonicated. Histone $\mathrm{H} 1(\mathrm{H} 1)$ and bovine myelin basic protein (MBP) were substrates for maturationpromoting factor (MPF; $\square$ ) and mitogen-activated protein (MAP) kinase (MAPK; $\mathbf{\square})$, respectively. After kinase reaction, the substrates were separated by SDS-PAGE, exposed to phosphor-screens and quantified using an FX Phosphor image analysis system (BioRad). (a) Phospho-image; (b) ${ }^{32} \mathrm{P}$ radioactivity representing kinase activities. Blank: 'hot' blank without oocytes.

p44Erk1, p42Erk2 MAP kinase polyclonal antibody (rabbit, 1:1000; New England Biolabs, Beverly, MA) in blocking buffer for $2 \mathrm{~h}$ at room temperature $\left(24^{\circ} \mathrm{C}\right)$. After three $15 \mathrm{~min}$ washes in TBST, the blots were incubated with horseradish peroxidase-conjugated goat anti-rabbit IgG antibody (1:2000; New England Biolabs) for $1 \mathrm{~h}$ at room temperature. After three further $15 \mathrm{~min}$ washes in TBST, the active p44Erk1, p42Erk2 MAP kinase was detected using enhanced chemiluminescence (Amersham Biosciences, Amersham).

\section{U0126 treatments}

Oocytes were cultured in either the synchronized or unsynchronized state to test the effect of U0126 (Promega) on MAP kinase activity and to determine the minimal doses required to inhibit MAP kinase activity completely in both DOs and COCs. For unsynchronized culture, COCs were either first cultured in DM for $28 \mathrm{~h}$ and then denuded and cultured as DOs in DM supplemented with $\cup 0126$ at 5, 10, 20, 25, 50 or
$100 \mu \mathrm{mol} \mathrm{I}^{-1}$ for a further $20 \mathrm{~h}$, or first cultured in DM for $18 \mathrm{~h}$ and then half the oocytes were cultured as COCs and half as DOs in DM supplemented with $50 \mu \mathrm{mol}$ $\mathrm{U} 0126 \mathrm{I}^{-1}$ for a further 10 or $30 \mathrm{~h}$ (without U0126 or at $0 \mu \mathrm{mol} \mathrm{I}^{-1}$ in controls). In the synchronized culture, COCs were first preincubated with cycloheximide for $12 \mathrm{~h}$ and then cultured either without cycloheximide but with $U 0126$ at $20,50,60,70$ or $80 \mu \mathrm{mol} \mathrm{I}{ }^{-1}$ as COCs, or without cycloheximide but with $\cup 0126$ at $10,20,30$ or $40 \mu \mathrm{mol} \mathrm{I}^{-1}$ as DOs for a further $12 \mathrm{~h}$. U0126 was prepared as a $10 \mathrm{mmol} \mathrm{I}^{-1}$ stock in dimethylsulphoxide (DMSO) and was added to DM to give the final concentrations required. Preliminary experiments had shown that DMSO at the concentrations used $(0.05-0.8 \%, v / v)$ in U0126 supplemented DM did not affect oocyte maturation.

The morphological effect of U0126 on meiotic maturation was evaluated by further culturing COCs and DOs without cycloheximide but with U0126 for various periods up to 28 and $14 \mathrm{~h}$, respectively, after preincubation for $12 \mathrm{~h}$ with cycloheximide. U0126 was used at $80 \mu \mathrm{mol} \mathrm{I}^{-1}$ for COCs and at 20 or $30 \mu \mathrm{mol} \mathrm{I}-1$ for DOs. The effect of U0126 on the activation of MPF was evaluated when MAP kinase was completely inhibited by $\cup 0126$ by further culturing COCs without cycloheximide but with $80 \mu \mathrm{mol} \cup 0126 \mathrm{I}^{-1}$ for various periods up to 12 or $28 \mathrm{~h}$, after preincubation for $12 \mathrm{~h}$ with cycloheximide.

\section{Statistical analysis}

One-way ANOVA with GenStat was used for evaluation of the results. A probability of $P<0.05$ was considered to be statistically significant.

\section{Results}

\section{Kinetics of MPF and MAP kinase activities during meiotic maturation}

In the two-step synchronized culture system, all oocytes were at GVII (100\%) after preincubation with cycloheximide and the majority progressed to MII $(>80 \%$ ) within $24 \mathrm{~h}$ of culture after the removal of cycloheximide. Upon removal of cycloheximide, the first population of oocytes underwent GVBD at $6 \mathrm{~h}$ $(28.6 \pm 4.5 \%)$, $\mathrm{Ml}$ at $10 \mathrm{~h}(42.9 \pm 10.8 \%)$, anaphase $\mathrm{I}-$ telophase I (AI-TI) at $16 \mathrm{~h}(13.3 \pm 7.2 \%)$ and MII at $20 \mathrm{~h}$ $(34.6 \pm 11.4 \%)$. Virtually no oocytes had reached the specified meiotic stages before these times. The maximal duration for each stage was $6 \mathrm{~h}$ for GVBD, $8 \mathrm{~h}$ for MI, $4 \mathrm{~h}$ for $\mathrm{Al}-\mathrm{TI}$ and $4 \mathrm{~h}$ for MII. Identical MI oocytes (cultured for $14 \mathrm{~h}$ after preincubation with cycloheximide) were used and the oocyte lysis method was optimized for the in vitro double-kinase assay, so that both kinase activities were reliably detectable even in single oocytes (MI) after probe sonication ( $5 \mu \mathrm{m}$ for $1-1.5 \mathrm{~s}$; Fig. 1). 
(a)

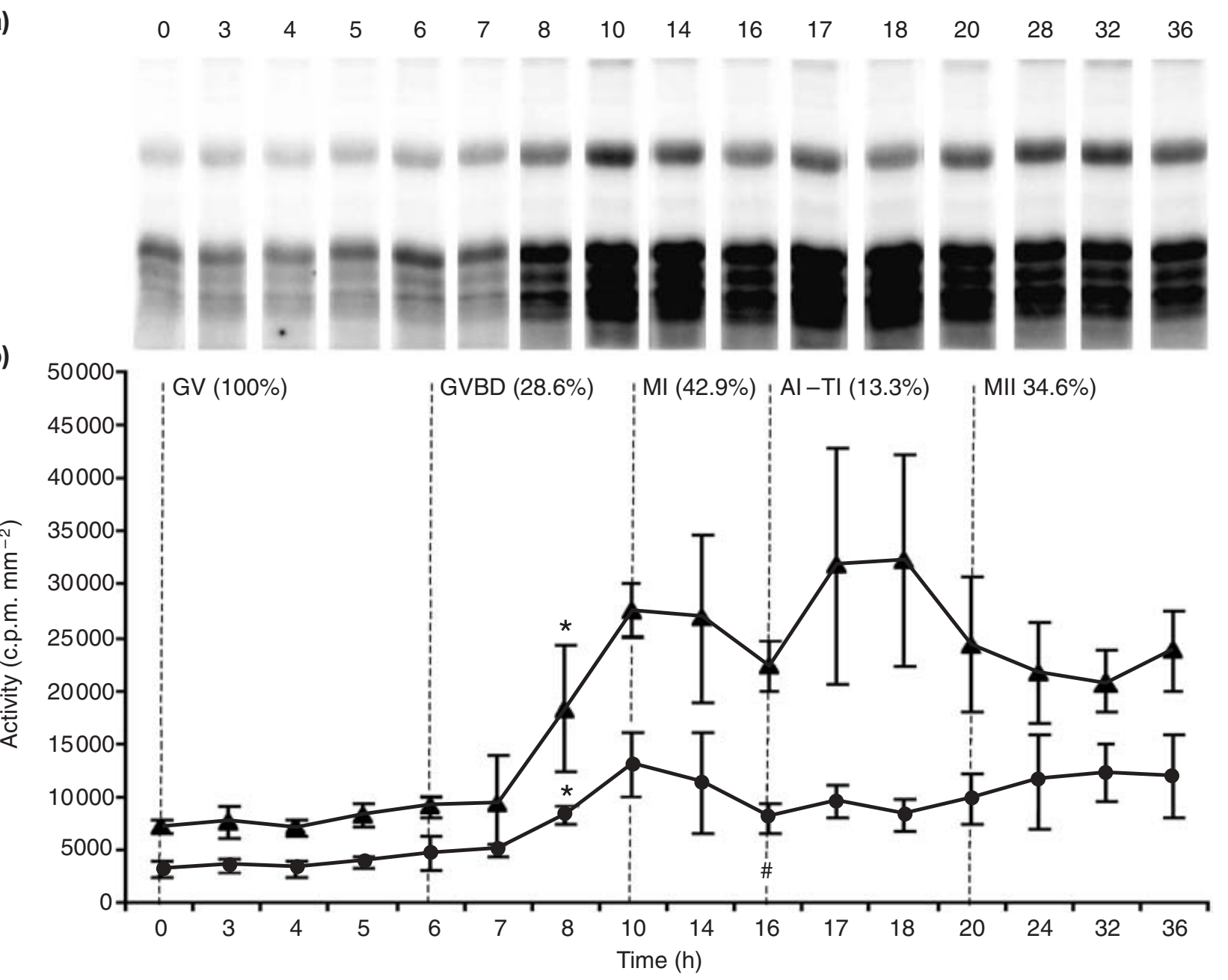

(b)

Fig. 2. General profiles of maturation-promoting factor (MPF; $\bullet$ ) and mitogen-activated protein (MAP) kinase (MAPK; $\mathbf{\Delta})$ activities during meiotic maturation in pig oocytes. Cumulus-oocyte complexes were first preincubated with cycloheximide for $12 \mathrm{~h}$ (from $0 \mathrm{~h}$ ) and then further cultured without cycloheximide for the periods indicated. At each time point, 10 oocytes were denuded and collected in $5 \mu$ l lysis buffer and sonicated. MPF and MAP kinase activities were measured with the in vitro double-kinase assay. (a) Phospho-images; (b) ${ }^{32} \mathrm{P}$ radioactivity representing kinase activities. The meiotic stages and proportions to which the first population of oocytes matured are indicated. Three replicates were performed. Data were log-transformed for analysis. GV: germinal vesicle; GVBD: germinal vesicle breakdown; MI: metaphase I; MII: metaphase II; AI-TI: anaphase I-telophase I. *,\#Significant increase or decrease in activity $(P<0.05)$ compared with that at 0 or $10 \mathrm{~h}$, respectively.

As preliminary experiments indicated that both kinases were inactivated in oocytes during preincubation with cycloheximide, the general profiles of kinase activities were determined in oocytes immediately after removal from cycloheximide $(0 \mathrm{~h})$. Both MPF and MAP kinase remained at basal activity during the first 5-6 h of maturation culture upon removal of cycloheximide (Fig. 2). The activities then increased in parallel, rising significantly at $7-8 \mathrm{~h}(P<0.05)$ and peaking at $10 \mathrm{~h}$. Whereas MAP kinase remained at peak activity for the rest of the culture period, the activity of MPF appeared to decrease during $14-20 \mathrm{~h}$ but increased to a sustained second peak after $24 \mathrm{~h}$ culture. The first peak of MPF activity correlated with MI, whereas the second correlated with MII; activity remained increased in association with the MII metaphase arrest.

The data in Fig. 2 were obtained in three parallel but separate assays. Although the general assay conditions were the same, interassay errors may have resulted from the use of separate gels, such that the results may not truly reflect the time-dependent difference in kinase activities. The timing of the activation or inactivation of MPF and MAP kinases around GVBD and during the MI-MII transition was defined more precisely by performing two independent experiments, with each batch of oocytes cultured for 3-10 or 12-24 h after removal of cycloheximide. This procedure allowed each 
(a)

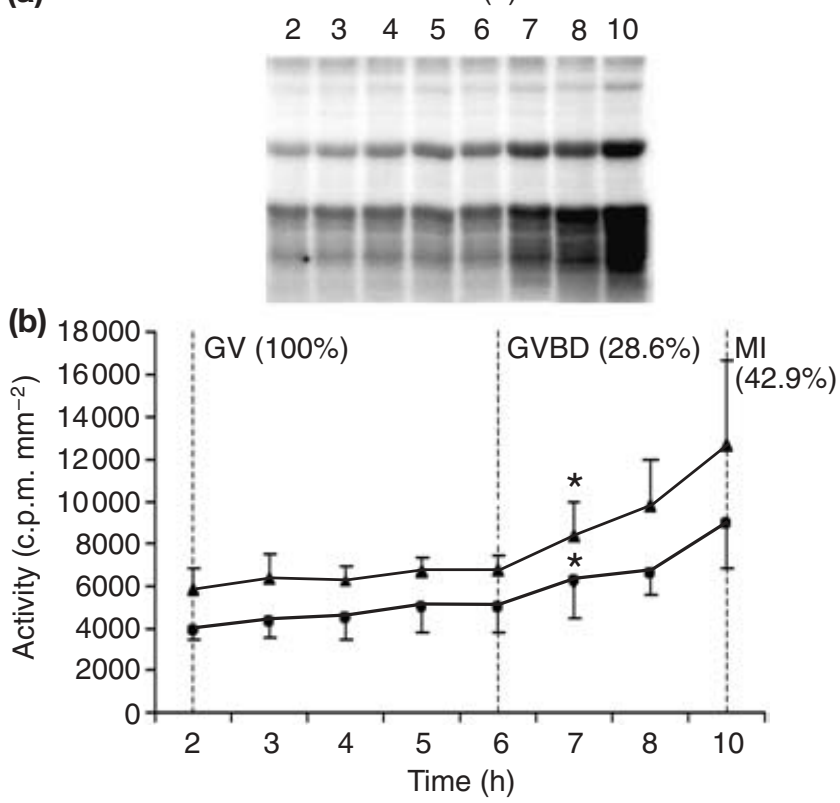

Fig. 3. Profiles of maturation-promoting factor (MPF; - ) and mitogen-activated protein (MAP) kinase (MAPK; $\mathbf{\Delta}$ ) activities during germinal vesicle breakdown (GVBD) in pig oocytes. Cumulusoocyte complexes were first preincubated with cycloheximide for $12 \mathrm{~h}$ (from $\mathrm{O} \mathrm{h}$ ) and then further cultured without cycloheximide for the periods indicated. At each time point, 10 oocytes were denuded and collected in $5 \mu \mathrm{l}$ lysis buffer and sonicated. MPF and MAP kinase activities were measured with the in vitro double-kinase assay. (a) Phospho-image; (b) ${ }^{32} \mathrm{P}$ radioactivity representing kinase activities. The meiotic stages and proportions to which the first population of oocytes matured are indicated. Five replicates were performed. Data were log-transformed for analysis. GV: germinal vesicle; MI: metaphase I. *Significant increase in activity $(P<0.05)$ compared with that at $2 \mathrm{~h}$.

series of samples to be loaded onto a single gel for SDS-PAGE after the in vitro kinase reaction. MPF and MAP kinases were activated concurrently and increased in parallel during GVBD (6-10 h), reaching significantly increased activity at $7 \mathrm{~h}(P<0.05$; Fig. 3). The activity of MPF significantly declined at $16-20 \mathrm{~h}(P<0.05)$ when $\mathrm{Al}-\mathrm{TI}$ appeared, started to increase again at $20 \mathrm{~h}$ when the first population of oocytes entered into MII, and peaked at $22 \mathrm{~h}$ (Fig. 4). However, MAP kinase remained stable at peak activity during the transition from $\mathrm{MI}$ to MII.

\section{Effects of the inhibition of MAP kinase by U0126 on meiotic progression and MPF activity}

U0126 is a specific and potent MEK-MAP kinase inhibitor (Favata et al., 1998; Goueli et al., 1998). The effective doses of U0126 required to inhibit MAP (a)

Time (h)

1214161718202224

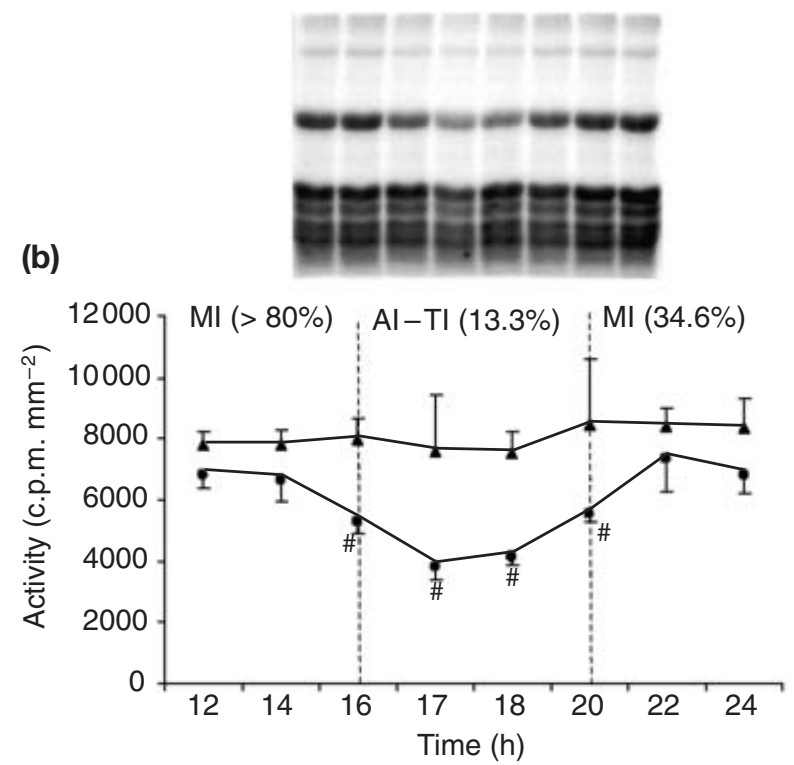

Fig. 4. Profiles of maturation-promoting factor (MPF; - ) and mitogen-activated protein (MAP) kinase (MAPK; $\mathbf{\Delta}$ ) activities during the metaphase I (MI)-MII transition in pig oocytes. Cumulus-oocyte complexes were first preincubated with cycloheximide for $12 \mathrm{~h}$ (from $0 \mathrm{~h}$ ) and then further cultured without cycloheximide for the periods indicated. At each time point, 10 oocytes were denuded and collected in $5 \mu \mathrm{l}$ lysis buffer and sonicated. MPF and MAP kinase activities were measured with the in vitro double-kinase assay. (a) Phospho-image; (b) ${ }^{32} \mathrm{P}$ radioactivity representing kinase activities. The meiotic stages and proportions to which the first population of oocytes matured were indicated accordingly (Ml $>80 \%$, the maximal proportion of $\mathrm{MI}$ ). Three replicates were performed. AI-TI: anaphase I-telophase I. "Significant decrease in activity $(P<0.05)$ compared with that at $12 \mathrm{~h}$.

kinase were determined in both COCs and DOs by either Western blotting or in vitro double-kinase assay. Oocytes were matured in either the synchronized or the unsynchronized state. U0126 inhibited the activation of MAP kinase in a dose-dependent manner (Figs 5-7). After $28 \mathrm{~h}$ of conventional culture, MAP kinase was fully activated in COCs (Ml; Fig. 5, lane 3). After denuding (DOs) and culturing for a further $20 \mathrm{~h}$ with $5 \mu \mathrm{mol}$ $\cup 0126 \mathrm{I}^{-1}$, MAP kinase activity was significantly inhibited, and with $20 \mu \mathrm{mol} \mathrm{I}{ }^{-1}$ or more it was completely blocked; MAP kinase was still fully activated in control oocytes (with $0 \mu \mathrm{mol} \cup 0126 \mathrm{I}^{-1}$; Fig. 5, lane 7). Compared with DOs, much higher concentrations of U0126 were required to inhibit MAP kinase in COCs completely. With $50 \mu \mathrm{mol} \cup 0126 \mathrm{I}^{-1}$, MAP kinase was still activated, at least in part, in COCs treated for $10 \mathrm{~h}$ after an initial $18 \mathrm{~h}$ conventional culture (Fig. 6, lane 4) or treated for $12 \mathrm{~h}$ after preincubation with cycloheximide (Fig. 7). 


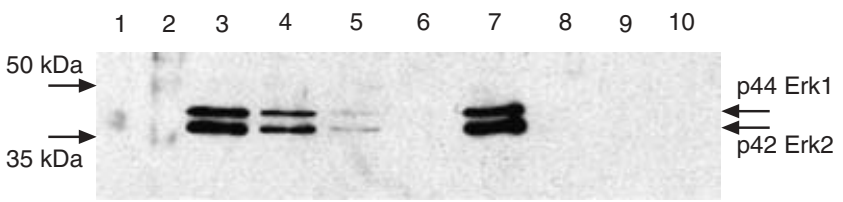

Fig. 5. Effects of U0126 on mitogen-activated protein (MAP) kinase (Erk1, 2) activity in denuded oocytes (DOs) in pigs, detected by western blot analysis. After an initial $28 \mathrm{~h}$ of conventional culture as cumulus-oocyte complexes, oocytes were denuded and further cultured as DOs with various concentrations of U0126 for $20 \mathrm{~h}$. Forty-five oocytes were collected in modified SDS sample buffer (see text) for analysis. Blots were probed with anti-phospho p44Erk1, p42Erk2 MAP kinase antibody (New England Biolabs). Lane 1: freshly isolated (germinal vesicle); lane 2: protein marker; lane 3: control $_{1}$ (cultured for $28 \mathrm{~h}$, metaphase I); lane 4: U0126 at $5 \mu \mathrm{mol} \mathrm{I}^{-1}$; lane 5: $10 \mu \mathrm{mol} \mathrm{I}{ }^{-1}$; lane 6: $20 \mu \mathrm{mol} \mathrm{I} \mathrm{I}^{-1}$; lane 7 : control $_{2}\left(0 \mu \mathrm{mol} \mathrm{I}{ }^{-1}\right)$; lane 8: $25 \mu \mathrm{mol} \mathrm{I}^{-1}$; lane 9: $50 \mu \mathrm{mol} \mathrm{I}{ }^{-1}$; and lane 10: $100 \mu \mathrm{mol} \mathrm{I} \mathrm{I}^{-1}$.

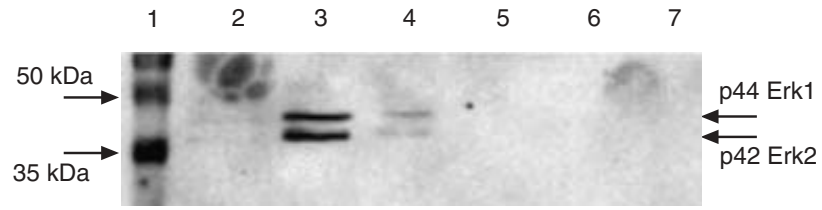

Fig. 6. Effects of U0126 on mitogen-activated protein (MAP) kinase (Erk1, 2) activity in both cumulus-oocyte complexes (COCs) and denuded oocytes (DOs) in pigs, detected with western blot analysis. After an initial $18 \mathrm{~h}$ of conventional culture as COCs, oocytes were further cultured as either COCs or DOs with $50 \mu \mathrm{mol}$ U0126 $\mathrm{I}^{-1}$ for 10 or 30 h. Forty-five oocytes were collected in modified SDS sample buffer (see text) for analysis. Blots were probed with antiphospho p44Erk1, p42Erk2 MAP kinase antibody (New England Biolabs). Lane 1: protein marker; lane 2: freshly isolated (germinal vesicle); lane 3: control (COCs cultured for $10 \mathrm{~h}$ without U0126); lane 4: COCs for $10 \mathrm{~h}$ with U0126; lane 5: DOs for $10 \mathrm{~h}$ with U0126; lane 6: COCs for $30 \mathrm{~h}$ with U0126; and lane 7: DOs for 30 h with $\cup 0126$.

However, treating with $50 \mu \mathrm{mol} \cup 0126 \mathrm{I}^{-1}$ for $30 \mathrm{~h}$ after an initial $18 \mathrm{~h}$ conventional culture (Fig. 6, lane 6) and with $80 \mu \mathrm{mol} \cup 0126 \mathrm{I}^{-1}$ for $12 \mathrm{~h}$ after the preincubation with cycloheximide (Fig. 7) reduced the activation of MAP kinase to control activity in COCs. Although MAP kinase activity was markedly reduced, the activation of MPF was not significantly affected (Fig. 7). Therefore, U0126 was used at 20 or $30 \mathrm{~mol} \mathrm{I}^{-1}$ (DOs) and $80 \mu \mathrm{mol} \mathrm{I}^{-1}$ (COCs) in further experiments.

As previous studies had demonstrated that DOs mature normally to $\mathrm{MI}$ but degenerate mostly thereafter (Ye et al., 2002), DOs were treated with 20 or $30 \mu \mathrm{mol}$ $\cup 0126 \mathrm{I}^{-1}$ for only $14 \mathrm{~h}$ after preincubation with cycloheximide to examine the effect of U0126 on the process of GVBD. DOs underwent GVBD and reached $\mathrm{MI}$ in the presence of 20 or $30 \mu \mathrm{mol} \cup 0126 \mathrm{I}^{-1}$, although the vast majority had an abnormal chromatin (a)

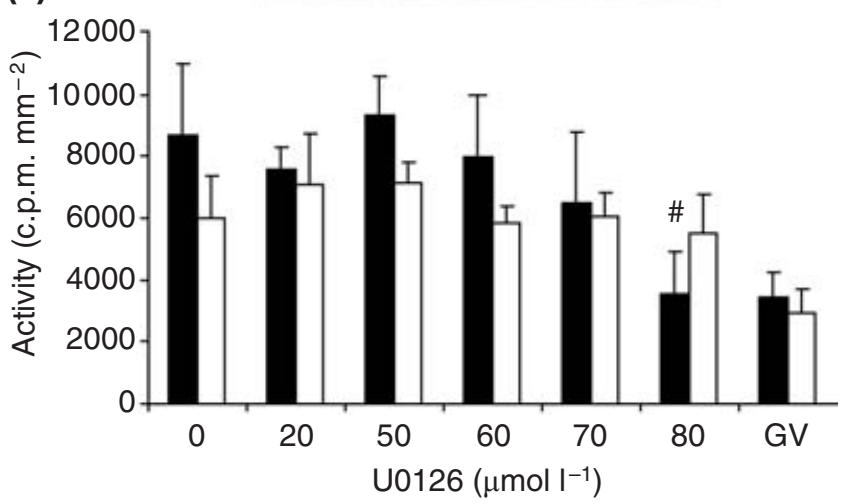

Fig. 7. Effects of U0126 on mitogen-activated protein (MAP) kinase (MAPK; - ) and maturation-promoting factor (MPF; $\square$ ) activities in cumulus-oocyte complexes (COCs) detected with the in vitro double-kinase assay in pigs. COCs were first preincubated with cycloheximide for $12 \mathrm{~h}$ (from $0 \mathrm{~h}$ ) and then further cultured for $12 \mathrm{~h}$ without cycloheximide but with $\mathrm{U} 0126$ at the concentrations indicated. Ten oocytes were denuded and collected in $5 \mu$ l lysis buffer and treated with probe sonication. (a) Phospho-image; (b) ${ }^{32} \mathrm{P}$ radioactivity representing kinase activities. Three replicates were performed. GV: germinal vesicle oocyte control as the background. \#Significant decrease in activity $(P<0.05)$ compared with that of control $\left(0 \mu \mathrm{mol} \cup 0126 \mathrm{I}^{-1}\right)$.

distribution at $\mathrm{MI}$ (Fig. 8a,c). COCs were cultured with $80 \mu \mathrm{mol} \cup 0126 \mathrm{I}^{-1}$ for various periods up to $28 \mathrm{~h}$ after preincubation with cycloheximide to check meiotic progression in more detail. COCs not only underwent normal GVBD in terms of chromatin morphology and timing but also matured to MII (> 80\%) after $24 \mathrm{~h}$ further culture (Fig. 9). Nevertheless, most oocytes had abnormal chromatin morphology at MI and MII (Fig. 8a,c,d). It appeared that with U0126, chromosomes condensed normally during GVBD but were arranged abnormally on the metaphase plate of the spindle. No general toxic effects of U0126 on the viability of DOs (20 or $\left.30 \mu \mathrm{mol} \mathrm{I}^{-1}\right)$ or COCs $\left(80 \mu \mathrm{mol} \mathrm{I} \mathrm{I}^{-1}\right)$ were revealed by Trypan blue staining. However, when U0126 was used at $100 \mu \mathrm{mol} \mathrm{I} \mathrm{I}^{-1}$, COCs rapidly lost viability and none survived after $8 \mathrm{~h}$ further culture after removal of cycloheximide.

The kinetics of both MPF and MAP kinase activities were determined during $12 \mathrm{~h}$ treatment with $80 \mu \mathrm{mol}$ U0126 $\mathrm{I}^{-1}$ to examine the effects of $\mathrm{U} 0126$ on the 

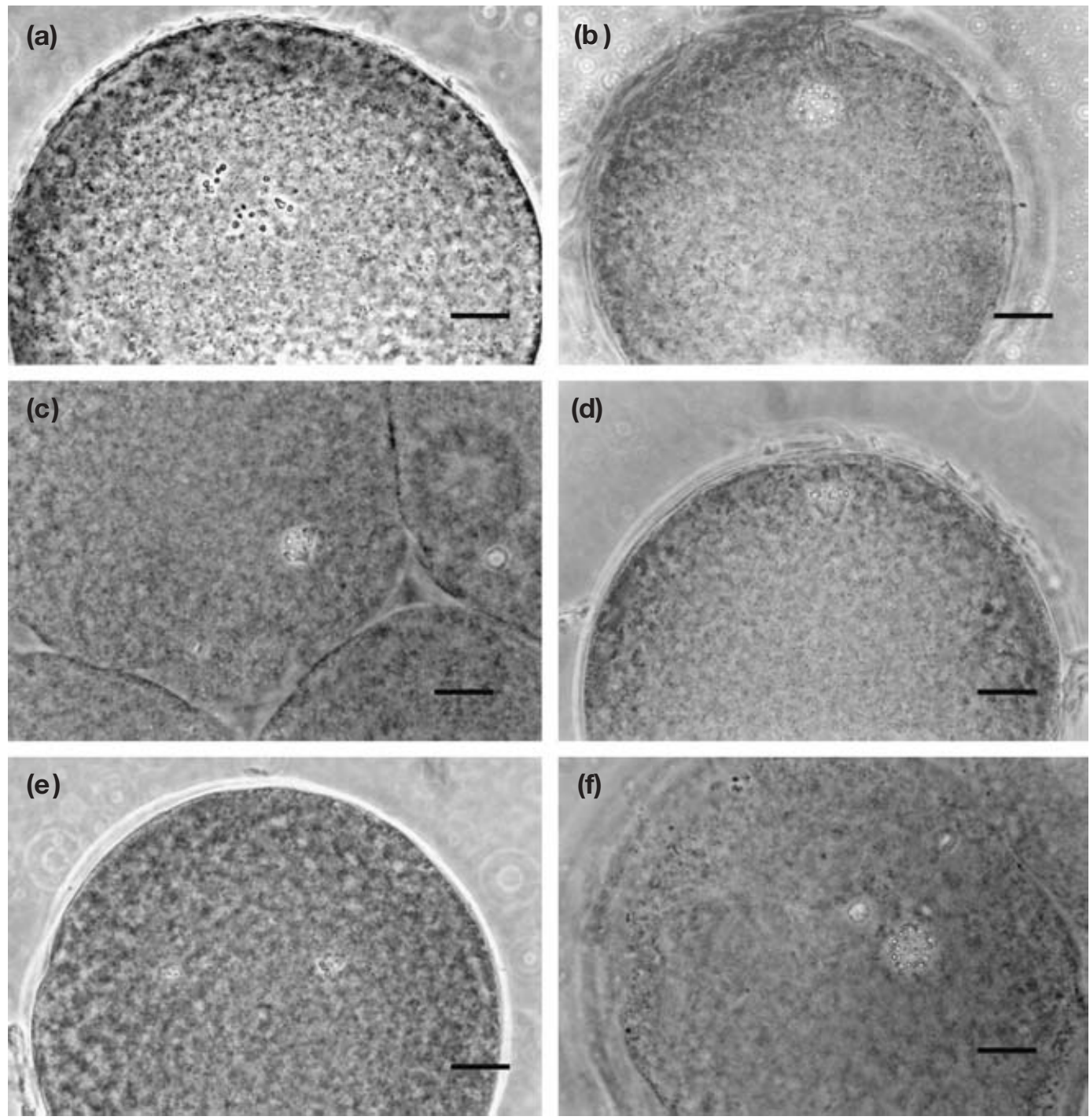

Fig. 8. Nuclear morphology of pig oocytes treated with U0126. After preincubation as cumulus-oocyte complexes (COCs) with cycloheximide for $12 \mathrm{~h}$ (from $0 \mathrm{~h}$ ), oocytes were either further cultured as denuded oocytes for $14 \mathrm{~h}$ without cycloheximide but with 20 or $30 \mu \mathrm{mol} \cup 0126 \mathrm{I}^{-1}$, or further cultured as COCs for various periods up to $28 \mathrm{~h}$ without cycloheximide but with $80 \mu \mathrm{mol} \cup 0126 \mathrm{I}^{-1}$. After assessing the viability by Trypan blue stain, oocytes were fixed and stained with lacmoid and examined under a phase-contrast microscope at $\times$ 400-1000 magnifications. (a,c) Abnormal metaphase I ( $\mathrm{Ml}$; at $14 \mathrm{~h})$, chromosomes were seen scattered irregularly, with or without a properly formed spindle; (b,d) control, normal MI; (e) abnormal MII (at $24 \mathrm{~h}$ ), although the first polar body had exited, the metaphase chromosomes were seen scattered irregularly, with or without a properly formed spindle; (f) normal MII (at 24 h, with U0126). Scale bars represent $20 \mu \mathrm{m}$.

activity of both kinases in detail. It was confirmed that MPF activation was not significantly affected by U0126 at GVBD although the total activity appeared slightly reduced; MAP kinase, in contrast, was completely inactivated (Fig. 10). The timing of MPF kinase activation was not altered by U0126 although the peak activity was slightly lower than in controls (12 h; Fig. 10). MAP kinase was inhibited and remained at basal activity by $80 \mu \mathrm{mol}$ U0126 $\mathrm{I}^{-1}$ not only during the $12 \mathrm{~h}$ culture but also during the entire $28 \mathrm{~h}$ culture after removal of cycloheximide (measured at $2 \mathrm{~h}$ intervals; data not shown).

\section{Discussion}

Meiotic progression in oocytes cultured in vitro commonly varies not only between laboratories but also between batches of oocytes. The variations between laboratories might result from differences in basic 


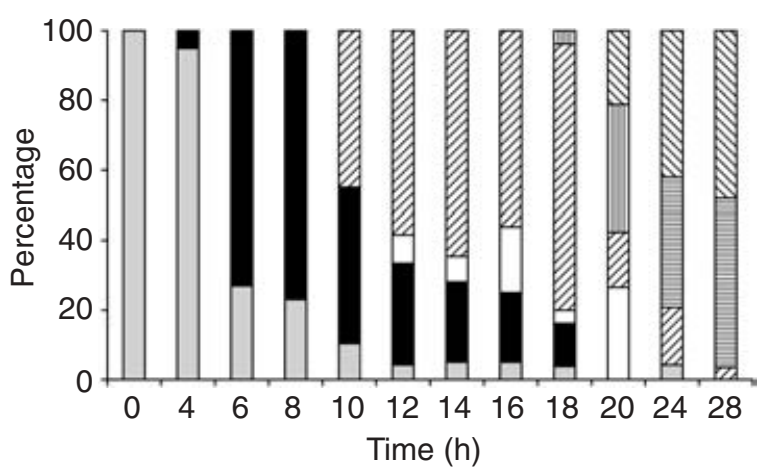

Fig. 9. Meiotic progression in cumulus-oocyte complexes (COCs) in pigs treated with U0126. COCs were first preincubated with cycloheximide for $12 \mathrm{~h}$ (from $0 \mathrm{~h}$ ) and then further cultured for various periods up to $28 \mathrm{~h}$ without cycloheximide but with 80 $\mu \mathrm{mol} \cup 0126 \mathrm{I}^{-1}$. At each time point, oocytes were fixed and stained with lacmoid to assess meiotic stages by phase-contrast microscopy. $\sqsubset$ : Germinal vesicle; $\boldsymbol{\square}$ : germinal vesicle breakdown (GVBD; diakinesis and prometaphase I; ᄃ: metaphase I; ש্]: abnormal metaphase I (see Fig. 8); 血: anaphase I-telophase I; 巨: metaphase II; : abnormal metaphase II (see Fig. 8).

culture conditions including culture media and oocyte source (sizes of selected follicles, layers of cumulus cell investments, age and oestrous cycle status of animals). The variations between batches are more likely to be due directly to oocytes. Pig oocytes are naturally heterogeneous in terms of meiotic status before selection for ovulation in vivo (Guthrie and Garrett, 2000). In addition, meiotic progression is asynchronous in conventional culture systems in vitro (Grupen et al., 1997; Ye et al., 2002). Heterogeneity and asynchrony of meiotic progression may be principal causes of polyspermic fertilization and poor development in pig oocytes (Funahashi et al., 1997a, b; Grupen et al., 1997), and these may also explain the reported differences in timing of the activation of MAP kinase. Motlik et al. (1998) suggested that disagreement about the kinetics of MPF or MAP kinase activities between researchers might be due to different culture systems. Contradictory conclusions may also arise from the same research groups. Inoue et al. (1995) first observed that MAP kinase activity significantly increases at MI with a transient slight decrease at $\mathrm{Al}-\mathrm{TI}$, and concluded that MAP kinase is involved in an event occurring after GVBD in pig oocytes. Subsequently, it was suggested that MAP kinase is activated before GVBD (Inoue et al., 1998; Sugiura et al., 2002). Other studies have shown that MAP kinase is activated at or around GVBD in pig oocytes (Motlik et al., 1998; Lee et al., 2000). None of these groups monitored the activity of MPF. Wehrend and Meinecke (2001) reported the profiles of both MPF and MAP kinase activities by simultaneous measurements with a double-kinase assay in pig oocytes. They observed that MAP kinase activity not only significantly increases before GVBD and MPF (a)
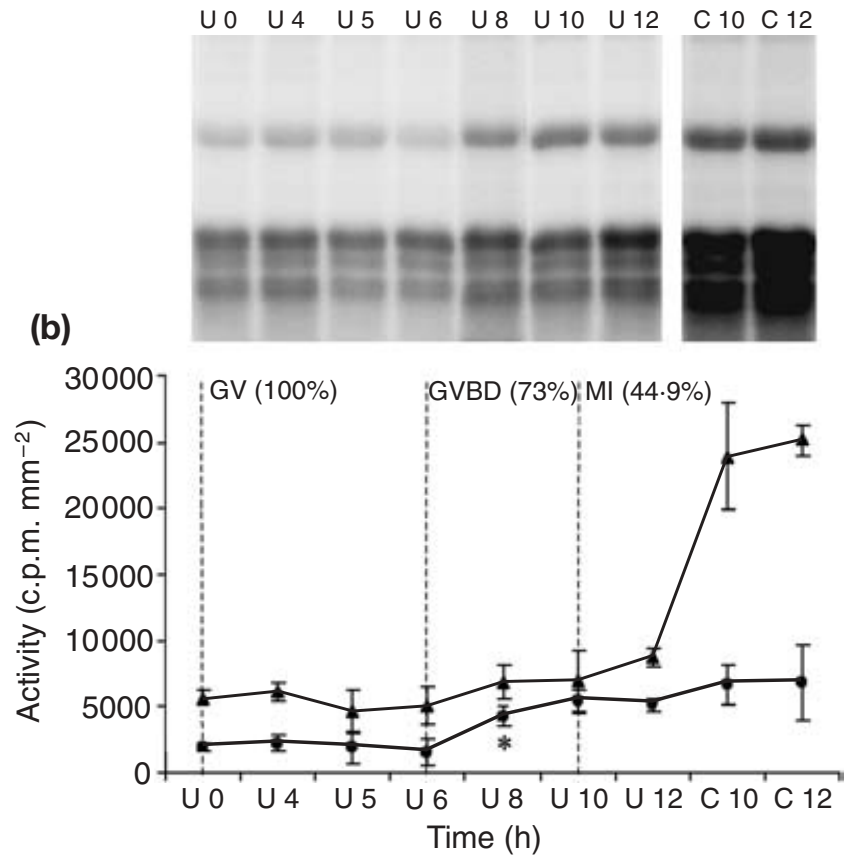

Fig. 10. Kinetics of maturation-promoting factor (MPF; 0 ) and mitogen-activated protein (MAP) kinase (MAPK; $\mathbf{\Delta}$ ) activities in cumulus-oocyte complexes (COCs) in pigs treated with U0126. COCs were first preincubated with cycloheximide for $12 \mathrm{~h}$ (from $0 \mathrm{~h}$ ) and then further cultured for various periods up to $12 \mathrm{~h}$ without cycloheximide but with $80 \mu \mathrm{mol} \cup 0126 \mathrm{I}^{-1}$. At each time point, 10 oocytes were denuded and collected in $5 \mu$ l lysis buffer and sonicated. MPF and MAP kinase activities were measured with the in vitro double-kinase assay. (a) Phospho-images; (b) ${ }^{32} \mathrm{P}$ radioactivity representing kinase activities. The meiotic stages and proportions to which the first population of oocytes matured are indicated. Three replicates were performed. GV: germinal vesicle; GVBD: germinal vesicle breakdown; MI metaphase I; U: U0126; C: control without U0126. ${ }^{*}$ Significant increase in activity $(P<0.05)$ compared with that at $0 \mathrm{~h}$.

but also continues to increase throughout the whole culture period, reaching a maximum activity at the end of $47 \mathrm{~h}$ of culture. Again, culture system differences and a lack of oocyte synchrony may explain the relatively early detection of MAP kinase activation and the increase in activity during the entire period of culture. It has been suggested that there may be two discrete populations of oocytes, starting at GVI and GVII-GVIV, and progressing through later meiotic stages to MII at 24 and 36 h, respectively (Grupen et al., 1997). Thus, in an unsynchronized culture system, the proportion of oocytes reaching MI or MII increases continuously over $48 \mathrm{~h}$ culture, resulting in the observed steady increase in MAP kinase activity.

The timing of MPF activation might also vary between studies. However, as it is believed that the MPF Cdc2 kinase is a conserved universal factor which induces G2-M cell-cycle transition in somatic cells or GVBD 
in oocytes (Masui and Markert, 1971; Nurse, 1990), variations in the timing of the activation of MPF may not attract much attention, even though the detected MPF or histone $\mathrm{H} 1$ kinase activation is actually after GVBD or ProMl (for example Mattioli et al., 1991; Naito and Toyoda, 1991). Unfortunately there is no commonly accepted view of the role of MAP kinase and its relationship with MPF in the initiation of meiotic maturation in oocytes, at least in pigs. Therefore, an improved approach to clarifying the temporal relationship between the two kinase activities would be simultaneous measurement using a double assay applied to a synchronized maturation culture system.

In pigs, as in other domestic species and frogs, but not mice, protein synthesis is a prerequisite for oocyte meiotic resumption. Cycloheximide, a nonspecific inhibitor of protein synthesis in eukaryotic cells, blocks the elongation of peptides by interacting with elongation factors and ribosomes (for review, see Vazquez, 1978). Early studies indicated that cycloheximide could reversibly block meiotic resumption in pig oocytes (Fulka et al., 1986). Ye et al. (2002) found that pig oocytes are not only temporarily blocked but also synchronized at a particular meiotic stage (GVII) by a $12 \mathrm{~h}$ preincubation with cycloheximide; the subsequent meiotic progression is also synchronized. The present results confirm that meiotic progression in pig oocytes is predictable in this two-step maturation culture system. Therefore, the oocyte samples used for kinase assays in this study reliably represent the intended meiotic stages. Probe sonication (5 $\mu \mathrm{m}$ for 1.0 $1.5 \mathrm{~s}$ ) was found to be the best method for lysing pig oocytes and preserving kinase activities, compared with other available methods including snap-freeze-thawing, cover-slide grating, glass-bead disruption and water-bath sonication (data not shown). The in vitro double-kinase assay proved to be highly sensitive, allowing activities to be reliably detected in a single MI oocyte. The relative activities between replicates were not calculated; therefore, the absolute quantity varied between, but not within, experiments.

The present results show that MPF and MAP kinases are both activated at approximately the same time at GVBD. The activities increase in parallel reaching significant activities at $7 \mathrm{~h}$, immediately after GVBD, and peaking after $10 \mathrm{~h}$ at MI. Thereafter, MAP kinase remains stable at peak activity during the MI-MII transition and at MII, whereas MPF activity significantly declines during the Ml-MIl transition (16-20 h) but increases again at MII. The present study demonstrates that MPF activation or inactivation coincides with that of meiotic morphology, and this agrees well with prevailing views on the role of MPF. In the synchronized culture system, GVBD took place abruptly at $6 \mathrm{~h}$ (about 29\% of the total oocytes), the only advanced meiotic stage compared with GV during the first 6-8 h culture after removal of cycloheximide. Therefore, a significant increase in
MPF (as well as MAP kinase) activity at $7 \mathrm{~h}$ reflected the first population of GVBD oocytes. The reason that the first significant MPF (as well as MAP kinase) activity was detected at $7 \mathrm{~h}$ but not at $6 \mathrm{~h}$ appeared to be the gradual activation of MPF at the beginning of GVBD (Naito and Toyoda, 1991). The $1 \mathrm{~h}$ delay between the detection of a significant increase in MPF activity and the start of GVBD was not likely to be a timing error, as all oocytes were handled and sampled identically for these experiments. Furthermore, there were at least two or three GVBD oocytes in each sample of ten oocytes at $6-7 \mathrm{~h}$, in which the activity of MPF was equivalent to $1.0-1.5 \mathrm{Ml}$ oocytes, according to Naito and Toyoda (1991), and therefore sufficient oocytes were present for the sensitivity of the in vitro double-kinase assay system in the present study.

Two MEK inhibitors, PD098059 and U0126, have been used to inhibit the activation of MAP kinase (Erk1, 2) in maturing oocytes (for example Kagii et al., 2000; Lee et al., 2000; Shimada et al., 2001; Tomek et al., 2002). Their mechanisms of inhibition are different: U0126 inhibits MEK directly, preventing endogenously active MEK1, 2 from phosphorylating and activating Erk1, 2, whereas PD098059 binds to the inactive enzyme, prevents its activation and indirectly inhibits activation of Erk1, 2. Thus, PD098059 may not be useful for inhibiting endogenously active MEK1, 2 and Erk1, 2 (Goueli et al., 1998). This may explain why PD098059 did not prevent MAP kinase activation in oocytes (for example, Tomek et al., 2002).

In the present study, $\cup 0126$ at $20 \mu \mathrm{mol} \mathrm{I}{ }^{-1}$ completely prevented MAP kinase activation in denuded pig oocytes, but a higher concentration $\left(80 \mu \mathrm{mol} \mathrm{I} \mathrm{I}^{-1}\right)$ was required to exert the same effect in COCs. That a higher dose was needed to inhibit the activation of MAP kinase in COCs than in DOs was probably due to reduced penetration of the drug into the oocyte which was surrounded by cumulus cells. Studies have shown that more than $85 \%$ of the metabolites derived from the culture medium enter the granulosa cells or cumulus cells first and subsequently reach the oocyte via gap junctions (Heller et al., 1981). Shimada et al. (2001) also observed inactivation by U0126 but found similar efficacy $\left(10-20 \mu \mathrm{mol} \mathrm{I}^{-1}\right)$ for both types of oocyte. Kagii et al. (2000) classified oocytes as GV or MII but did not synchronize meiotic progression; they found that U0126 at a dose as high as $100 \mu \mathrm{mol} \mathrm{I} \mathrm{I}^{-1}$ only partially inhibited the activation of MAP kinase in COCs, and had no effect on MAP kinase in DOs. This finding led to the suggestion that MAP kinase is required for meiotic resumption in pig oocytes. In the present study, $100 \mu \mathrm{mol} \cup 0126 \mathrm{I}^{-1}$ killed COCs within $8 \mathrm{~h}$ of culture. The reason for this difference in observed toxicity is not clear. The similarity of doses needed for effective inhibition of MAP kinase in oocytes and for lethality when applied to COCs indicates that there are thresholds both for the disturbance of gap junctions between cumulus cells and oocytes (Shimada 
et al., 2001), and for the general toxicity of the chemical on oocytes.

As the in vitro double-kinase assay is based on the phosphorylation of $\mathrm{MBP}$ and histone $\mathrm{H} 1$, other kinases might also contribute to the measured activities. However, in the assay system used in the present study, any such residual MAP kinase activity in oocytes treated with $80 \mu \mathrm{mol} \cup 0126 \mathrm{I}^{-1}$ must have been almost as strong as in GV oocytes and can be considered an assay background activity. MPF and MAP kinase may cross-contaminate double in vitro kinase assays (Shibuya et al., 1992; Nebreda et al., 1995), but in the present system the contribution of MPF kinase activity towards measured MAP kinase activity was very low, as shown in U0126-treated and control oocytes. Nevertheless, crossphosphorylation of histone $\mathrm{H} 1$ by MAP kinase may explain why the measured activity of MPF was slightly reduced when MAP kinase was inhibited by U0126.

In agreement with Shimada et al. (2001), the present results demonstrate that oocytes in which the activation of MAP kinase is completely prevented still undergo normal GVBD and even reach MII. The activation of MPF corresponds well to the timing of GVBD even though the activation of MAP kinase has been completely prevented, indicating that MPF is sufficient to induce GVBD. The results also support the idea that MAP kinase may be involved in arranging chromosomes on the metaphase spindle plate, as has been previously indicated (for review, see Sun et al., 1999).

\section{References}

Barrett CB, Schroetke RM, Vanderhoorn FA, Nordeen SK and Maller JL (1990) Ha-rasVal-12,Thr-59 activates S6 kinase and p34cdc2 kinase in Xenopus oocytes - evidence for c-mosxe-dependent and c-mosxeindependent pathways Molecular and Cellular Biology 10 310-315

Dedieu T, Gall L, Crozet N, Sevellec C and Ruffini S (1996) Mitogenactivated protein kinase activity during goat oocyte maturation and the acquisition of meiotic competence Molecular Reproduction and Development 45 351-358

Denhardt DT (1999) Signal transduction pathways and regulation of the mammalian cell cycle:cell type-dependent integration of external signals. In The Molecular Basis of Cell Cycle and Growth Control pp 225-304 Eds GS Stein, R Baserga, A Giordano and DT Denhardt. John Wiley \& Sons Inc., New York

Favata MF, Horiuchi KY, Manos EJ et al. (1998) Identification of a novel inhibitor of mitogen-activated protein kinase kinase Journal of Biological Chemistry 273 18623-18632

Ferrell JE, Jr (1996) MAP kinases in mitogenesis and development Current Topics in Developmental Biology 33 1-60

Fisher DL, Brassac T, Galas S and Doree M (1999) Dissociation of MAP kinase activation and MPF activation in hormone-stimulated maturation of Xenopus oocytes Development 126 4537-4549

Fissore RA, Chang LH and Woude GFV (1996) Potential role of mitogenactivated protein kinase during meiosis resumption in bovine oocytes Biology of Reproduction 55 1261-1270

Fulka J, Jr, Motlik J and Jilek F (1986) Effect of cycloheximide on nuclear maturation of pig and mouse oocytes Journal of Reproduction and Fertility 77 281-285

Funahashi H, Cantley TC and Day BN (1997a) Synchronisation of meiosis in porcine oocytes by exposure to dibutyryl cyclic adenosine monophosphate improves developmental competence following in vitro fertilisation Biology of Reproduction 57 49-53

Funahashi H, Cantley TC and Day BN (1997b) Preincubation of cumulusoocyte complexes before exposure to gonadotrophins improves the developmental competence of porcine embryos matured and fertilised in vitro. Theriogenology 47 679-686

Gautier J, Norbury C, Lohka M, Nurse P and Maller J (1988) Purified maturation-promoting factor contains the product of a Xenopus homolog of the fission yeast-cell cycle control gene cdc2+ Cell 54 433-439

Goueli SA, Hsiao K, Lu T and Simpson D (1998) U0126: a novel, selective and potent inhibitor of MAP kinase kinase (MEK) Promega Notes Magazine 69 6-8

Gross SD, Schwab MS, Taieb FE, Lewellyn AL, Qian YW and Maller JL (2000) The critical role of the MAP kinase pathway in meiosis II in Xenopus oocytes is mediated by p90(Rsk) Current Biology 10 430-438

Grupen CG, Nagashima H and Nottle MB (1997) Asynchronous meiotic progression in porcine oocytes matured in vitro: a cause of polyspermic fertilization? Reproduction, Fertility and Development 9 187-191

Guthrie HD and Garrett WM (2000) Changes in porcine oocyte germinal vesicle development as follicles approach preovulatory maturity Theriogenology 54 389-399

Heller DT, Cahill DM and Schultz RM (1981) Biochemical studies of mammalian oogenesis-metabolic cooperativity between granulosa-cells and growing-mouse oocytes Developmental Biology 84 455-464

Inoue M, Naito K, Aoki F, Tayoda Y and Sato E (1995) Activation of mitogenactivated protein kinase during meiotic maturation in porcine oocytes Zygote 3 265-271

Inoue M, Naito K, Nakayama T and Sato E (1998) Mitogen-activated protein kinase translocates into the germinal vesicle and induces germinal vesicle breakdown in porcine oocytes Biology of Reproduction 58 130136

Kagii H, Naito K, Sugiura K, Iwamori N, Ohashi S, Goto S, Yamanouchi K and Tojo H (2000) Requirement of mitogen-activated protein kinase activation for the meiotic resumption of porcine oocytes Journal of Reproduction and Development 46 249-256

Krischek C and Meinecke B (2001) Roscovitine, a specific inhibitor of cyclindependent protein kinases, reversibly inhibits chromatin condensation during in vitro maturation of porcine oocytes Zygote 9 309-316

Kubelka M, Kalab P, Kalous J, Nagyova E and Motlik J (1996) The effect of butyrolactone I, a specific inhibitor of cdk-kinases on GVBD and chromosome condensation during the first meiotic division of pig and cattle oocytes Archiv Fur Tierzucht - Archives of Animal Breeding 3953

Kubelka M, Anger M, Kalous J, Schultz RM and Motlik J (2002) Chromosome condensation in pig oocytes: lack of a requirement for either cdc2 kinase or MAP kinase activity Molecular Reproduction and Development 63 110-118

Laemmli UK (1970) Cleavage of structural proteins during the assembly of the head of bacteriophage T4 Nature 227 680-685

Langan TA, Gautier J, Lohka M, Hollingsworth R, Moreno S, Nurse P, Maller J and Sclafani RA (1989) Mammalian growth-associated h-1 histone kinase - a homolog of cdc2+/cdc28 protein-kinases controlling mitotic entry in yeast and frog cells Molecular and Cellular Biology 9 3860-3868

Lee J, Miyano T and Moor RM (2000) Localisation of phosphorylated MAP kinase during the transition from meiosis I to meiosis II in pig oocytes Zygote 8 119-125

Li MY, Fan HY, Tong C, Chen DY, Xia GL and Sun QY (2002) MAPK regulates cell cycle progression in pig oocytes and fertilized eggs Chinese Science Bulletin 47 843-846

Lohka MJ, Hayes MK and Maller JL (1988) Purification of maturationpromoting factor, and intracellular regulator of early mitotic events Proceedings National Academy of Sciences USA 85 3009-3013

Masui Y (2000) The elusive cytostatic factor in the animal egg Nature Reviews Molecular Cell Biology $1228-232$

Masui Y and Markert CL (1971) Cytoplasmic control of nuclear behavior during meiotic maturation of frog oocytes Journal of Experimental Zoology 177 129-145

Mattioli M, Galeati G, Bacci ML and Barboni B (1991) Changes in maturation-promoting activity in the cytoplasm of pig oocytes 
throughout maturation Molecular Reproduction and Development 30 119-125

Meinecke B, Janas U, Podhajsky E and Meinecke-Tillmann S (2001) Histone $\mathrm{H} 1$ and MAP kinase activities in bovine oocytes following protein synthesis inhibition Reproduction in Domestic Animals 36 183-188

Moor RM, Mattioli M, Ding J and Nagai T (1990) Maturation of pig oocytes in vivo and in vitro. Journal of Reproduction and Fertility Supplement 40 197-210

Motlik J, Pavlok A, Kubelka M, Kalous J and Kalab P (1998) Interplay between cdc2 kinase and map kinase pathway during maturation of mammalian oocytes Theriogenology 49 461-469

Naito K and Toyoda Y (1991) Fluctuation of histone-H1 kinase-activity during meiotic maturation in porcine oocytes Journal of Reproduction and Fertility 93 467-473

Nebreda AR and Ferby I (2000) Regulation of the meiotic cell cycle in oocytes Current Opinion in Cell Biology 12 666-675

Nebreda AR and Hunt T (1993) The c-mos proto-oncogene protein kinase turns on and maintains the activity of MAP kinase, but not MPF, in cellfree-extracts of Xenopus-oocytes and eggs EMBO Journal 12 1979-1986

Nebreda A, Gannon J and Hunt T (1995) Newly synthesised protein(s) must associate with p34cdc2 to activate MAP kinase and MPF during progesterone-induced maturation of Xenopus oocytes EMBO Journal 14 5579-5607

Nurse P (1990) Universal control mechanism regulating onset of M-phase Nature 344 503-508

Palmer A, Gavin AC and Neberda AR (1998) A link between MAP kinase and p34cdc2/cyclin B during oocyte maturation: p90rsk phosphorylates and inactivates the p34cdc2 inhibitory kinase Myt1 EMBO Journal 17 5034-5047

Posada J, Yew N, Ahn NG, Vandewoude GF and Cooper JA (1993) Mos stimulates map kinase in Xenopus oocytes and activates a map kinase kinase in vitro. Molecular and Cellular Biology 13 2546-2553

Puri PL, MacLachlan TK, Levrero M and Giordano A (1999) The intrinsic cell cycle: from yeast to mammals. In The Molecular Basis of Cell Cycle and Growth Control pp 15-79 Eds GS Stein, R Baserga, A Giordano and DT Denhardt. John Wiley \& Sons Inc., New York

Sagata N, Watanabe N, Vandewoude GF and Ikawa Y (1989) The C-mos proto-oncogene product is a cytostatic factor responsible for meiotic arrest in vertebrate eggs Nature 342 512-518

Shibuya EK, Boulton TG, Cobb MH and Ruderman JV (1992) Activation of p42 map kinase and the release of oocytes from cell cycle arrest $E M B O$ Journal 11 3963-3975

Shimada M, Zeng WX and Terada T (2001) Inhibition of phosphatidylinositol 3-kinase or mitogen-activated protein kinase kinase leads to suppression of $\mathrm{p} 34 \mathrm{cdc} 2$ kinase activity and meiotic progression beyond the meiosis I stage in porcine oocytes surrounded with cumulus cells Biology of Reproduction 65 442-448

Sugiura K, Naito K, Iwamori N, Kagii H, Goto S, Ohashi S, Naruoka H, Yada E, Yamanouchi K and Tojo H (2002) Activation of ribosomal S6 kinase (RSK) during porcine oocyte maturation Zygote 10 31-36

Sun QY, Breitbart H and Schatten H (1999) Role of the MAPK cascade in mammalian germ cells Reproduction, Fertility and Development 11 443-450

Sun QY, Wu GM, Lai LX, Bonk A, Cabot R, Park KW, Day BN, Prather RS and Schatten H (2002) Regulation of mitogen-activated protein kinase phosphorylation, microtubule organization, chromatin behavior, and cell cycle progression by protein phosphatases during pig oocyte maturation and fertilization in vitro. Biology of Reproduction 66580 588

Tomek W, Sterza FAM, Kubelka M, Wollenhaupt K, Torner H, Anger $\mathbf{M}$ and Kanitz W (2002) Regulation of translation during in vitro maturation of bovine oocytes: the role of MAP kinase, elF4E (cap binding protein) phosphorylation, and elF4E-BP1 Biology of Reproduction 66 1274-1282

Vazquez D (1978) Translation inhibitors. In International Review of Biochemistry: Amino Acid and Protein Biosynthesis II Vol. 18 pp 207208 Ed. HRV Arnstein. University Park Press, Baltimore

Wehrend A and Meinecke B (2001) Kinetics of meiotic progression, Mphase promoting factor (MPF) and mitogen-activated protein kinase (MAP kinase) activities during in vitro maturation of porcine and bovine oocytes: species specific differences in the length of the meiotic stages Animal Reproduction Science 66 175-184

Yamashita M, Mita K, Yoshida N and Kondo T (2000) Molecular mechanisms of the initiation of oocyte maturation: general and species-specific aspects. In Progress in Cell Cycle Research Vol. 4 pp 115-129 Eds L Meijer, A Jezequel and B Ducommun. Kluwer Academic/Plenum Publishers, New York

Ye J, Flint APF, Campbell KHS and Luck MR (2002) Synchronisation of porcine oocyte meiosis using cycloheximide and its application to the study of regulation by cumulus cells Reproduction, Fertility and Development 14 433-442

Received 26 November 2002.

First decision 13 January 2003.

Revised manuscript received 5 February 2003.

Accepted 6 February 2003. 